\title{
Aggregate Australian Takeovers: A Review of Markov Regime Switching Models
}

\author{
Lien Duong*
}

Paper Date: 2 September 2013

\begin{abstract}
This paper reviews the case of modelling merger waves in the Australian market for the period 1972 to 2004. Three Markov switching models are examined, the Gaussian AR(1), Poisson $\operatorname{AR}(1)$ and State-Space $\operatorname{ARMA}(1,1)$, to find which gives the best fit. The StateSpace Markov switching ARMA(1,1) model is found to be the best for describing Australian takeover activity as estimation results based on it have a lower Bayesian information criterion (BIC) score than the other two models. Each model's ability to predict a "wave" is then tested by including its estimated probability in a macro-economic model to explain merger activity. The State-Space model also performs better because the inclusion of its estimated probability substantially increases the explanatory power of the regression model (measured by the regression adjusted $R^{2}$ ). In addition, it predicted a takeover wave in 2009 , which was closer to the actual incidents of takeover activity in the market at that time than the predictions of the other two models. The results are robust when the measure of takeover activity is changed from the number of takeover bids to the proportion of takeover bids relatively to the number of exchange-listed companies.
\end{abstract}

Keywords: Merger and acquisitions, Merger waves, State-space Markov switching model, Macro-economic factors.

JEL classification: G34, C32.

*Lien Duong (l.duong@curtin.edu.au) is Senior Lecturer at the School of Accounting, Curtin University, Australia. The author would like to acknowlege the insightful comments and suggestions made by an anonymous referee, Sudipto Dasgupta (Editor), Izan H.Y Izan, and Duc-Son Pham. All errors remain the responsibility of the author. (Paper received November 2012, revised version accepted August 2013).

Address for correspondence: Lien Duong, School of Accounting, Curtin University, Bentley campus, GPO Box U1987, Perth, Western Australia 6845 


\section{Introduction}

Takeover activity varies episodically with episodes of high incidences of takeover bids commonly termed "merger waves". Many studies have reported wave patterns in merger activity (e.g. Mitchell and Mulherin, 1996; Andrade et al., 2001), and a vast range of empirical literature has sought to identify potential causes and triggers of merger waves (e.g. Shleifer and Vishny, 2003; Rhodes-Kropf and Viswanathan, 2004; Harford, 2005; Gorton et al., 2009; Banal-Estanol et al., 2010). While the notion that takeovers vary in incidence over time is undisputed, there is no consensus on how to describe "merger waves" in a time-series context. For example, Chowdhury (1993) contends that merger and acquisition (M\&A) activity is random and hence unpredictable, while other authors argue that takeover series can be modelled. Amongst the latter group, there is disagreement about how best to model this behaviour. Some authors (Shughart and Tollison, 1984; Barkoulas et al., 2001) claim that M\&A activity can best be described as a linear process (namely, an autoregressive process), as a result of which, merger waves do not exist. Other authors (Town, 1992; Linn and Zhu, 1997; Kendig, 1997; Gartner and Halbheer, 2009; Duong and Izan, 2012) argue that a non-linear model, specifically a two-state Markov switching model, should be used to characterise M\&A time series.

In this paper, the case of modelling merger waves in Australia is reviewed with regard to recent trends in M\&As. A preliminary analysis on the number of Australian takeover bids data rejects the presence of a linear structure (autoregressive (AR) process) in the time series. ${ }^{1}$ The strong rejection of a linear model suggests that the time series of M\&A activity may be best described by non-linear models. The literature has shown that the rejection of the linear AR model may be traced to structural shifts in the mean of the takeover series. Merger data are observed to have clear periods of high and low activity, with high level activity occurring intensively over short periods. A two-state Markov switching approach is ideally suited to describe these differences, where discrete shifts in regime occur between a merger "wave" state and a "normal" state (Hamilton, 1989). One of the great advantages of this model is that it enables the prediction of waves, and potentially provides an insight into exogenous factors motivating the takeover regime shifts. This paper, therefore, evaluates all the two-state Markov switching models in the Australian literature and makes recommendations of the "best" model.

There are currently two Markov switching models specifically applied to takeover data in the Australian market. They are Poisson Markov switching AR(1) model (Kendig, 1997), and State-

\footnotetext{
${ }^{1}$ Tests for the existence of linear structure are in two parts. First, tests are conducted to examine if the data and various levels of differencing exhibit white noise characteristics. The tests used are the Ljung-Box test (Ljung and Box, 1978) and the Brock, Dechert, Scheinkman \& LeBaron (BDSL) test (Brock et al., 1996). Secondly, in order to test for any linear structure inside the data, an AR model (from AR(1) up to AR(6)) is fitted and the residuals are investigated for white noise characteristics using the same tests. The results show that the rejection of a linear model is very strong.
} 
Space Markov switching ARMA(1,1) model (Duong and Izan, 2012). As both models are derived from the Gaussian Markov switching AR(1) model of Hamilton (1989), it is necessary to include this model in the comparison although it is primarily used to characterise US takeovers (Town, 1992; Linn and Zhu, 1997). In order to facilitate a consistent assessment, the same dataset should be applied to all models. This paper is, therefore, based on the dataset of Duong and Izan (2012) as it contains the most up-to-date Australian takeover data. ${ }^{2}$

The study begins by examining the three Markov switching models, using the number of Australian takeover bids ${ }^{3}$ from 1972 to 2004 . Takeover data is initially fitted to each model and then a number of techniques are employed for model selection: the Bayesian information criterion (BIC) score, ability in predicting future waves, and ability in explaining takeover activity in the regression with macro-economic variables. The best model is chosen for its lowest BIC score, highest adjusted R-square in the regression, and closest prediction of the future wave when compared with the actual takeover activity. This turns out to be the State-Space Markov switching ARMA $(1,1)$ model. The result is robust even when the measure of takeover activity is changed to the proportion of takeover bids relative to the number of exchange-listed companies.

This study contributes to the literature by recommending a "good" model of takeover waves for the Australian market. Choosing a suitable model to characterise the behaviour of takeover activity is crucial since takeover activity is a significant part of the Australian corporate market landscape. ${ }^{4}$ M\&As are transactions of great significance, not only to the companies themselves, but to many other constituencies, such as workers, managers, communities and the economy. ${ }^{5}$ There is evidence that bidders in merger waves earn, on average, lower long-term abnormal returns than those who initiate their bids in non-wave periods (e.g. Harford, 2003a; Rosen, 2006; Gugler et al., 2006; Duong and Izan, 2012; Duchin and Schmidt, 2013). As market participants suffer a potential economic redistribution from the effects of merger wave, understanding and

\footnotetext{
${ }^{2}$ Kendig (1997)'s model covers Australian takeover data to 1995, while Duong and Izan (2012)'s model expands it to 2004 .

${ }^{3}$ All the authors (Hamilton, 1989; Kendig, 1997; Duong and Izan, 2012) have only used the number of bids as takeover measure in the analyses of their Markov switching models.

${ }^{4}$ An average of $8.13 \%$ of listed Australian firms was subject to a takeover bid for each year between 1960 and 1988 (Bureau of Industry Economics, 1990). In 2004 alone Australia had 1,440 merger and acquisition (M\&A) deals totalling $\$ 116$ billions ( "The Australian", 5 January 2005), equivalent to over $10 \%$ of the share market value of all publicly listed companies on the Australian Securities Exchange (ASX) (the Australian national stock market is the second largest after Japan in the Asia-Pacific by market capitalisation). The total value of Australian M\&A activity for the first quarter of 2005 accounted for half of the total deals recorded in the Asia-Pacific region with 225 deals worth $\$$ A27.4 billions ( "Australian Associated Press Financial News Wire", 30 March 2005).

${ }^{5}$ Shareholders may lose their investment because of imprudent acquisitions made by their companies. Target directors may have difficulty in the managerial labour market later as Harford (2003b) finds that target directors hold fewer directorships in the future. Acquiring companies are often motivated by the need to make efficiency savings in production and other activities. which are usually achieved at cost to workers in the form of job losses and to communities in the form of terminated economic activity from the closing of plants and factories. For instance, after winning control of WMC Resources in early June 2006, BHP Billiton announced that there would be hundreds of job losses at WMC's corporate headquarters in Melbourne ("BHP parachutes board into WMC", http://www.timesonline.co.uk, 6 June 2005).
} 
predicting such waves are essential.

In choosing the right model to characterse takeover activity, a new set of selection criteria are developed to compare the two current Markov switching models in Australia, ${ }^{6}$ and to investigate any improvements in them from the original US model. ${ }^{7}$ Although there are some similarities between Australia and the US, distinctions are noticeable in their takeover markets so it is desirable to have different takeover models for each country. While Australia is a smaller market for corporate control, both countries have similar corporate cultures focusing on shareholder interests and both experience the cyclical wave pattern of merger activity. The level of hostile takeover bids is one of the most significant differences between the US and Australian market. Hostile bids in the US market accounted for only $0.57 \%$ of all takeover bids over the period 1990-2005 (Armour and Skeel, 2007), whereas they made up 19\% of the Australian market from 1992 to 2001 (Dignam and Galanis, 2004). This reflects a distinctive feature in the takeover legislation of each country, with the US law allowing target company managers more flexibility in implementing defensive measures against bidders. Australian takeover law is less favourable to target managers than its American counterpart. Takeover defence mechanisms, such as poison pills, are more prevalent in the US, while it is very limited in Australia. ${ }^{8}$

Another contribution of this study is to apply the most recent takeover data to the switching models of Kendig (1997) and Hamilton (1989) in order to offer a consistent comparison with Duong and Izan (2012)'s model. Finally, this study extends previous research by including both the number of takeover bids and their proportion relative to the number of exchanged-listed companies as takeover measurements. Previous studies (Hamilton, 1989; Kendig, 1997; Duong and Izan, 2012) base their analyses only on the number of takeover bids. As the number of companies listed on the Australian Securities Exchange (ASX) changes over time, it is necessary to take company growth into account.

The remainder of this paper is organised as follows. Section I provides an overview of the modelling of takeover activity. Section II describes the data collection of takeover bids. Section III reviews the three Markov switching models. The criteria for model selection are outlined in Section IV. The estimation results are presented in Section V, and Section VI presents the conclusions.

\footnotetext{
${ }^{6}$ The two Australian models are Poisson Markov switching AR(1) model of Kendig (1997), and State-Space Markov switching ARMA(1,1) model of Duong and Izan (2012).

${ }^{7}$ The Gaussian Markov switching AR(1) model of Hamilton (1989) is predominantly used in the US studies (Town, 1992; Linn and Zhu, 1997).

${ }^{8}$ Poison pills are virtually non-existent in Australia. This is a major reason for News Corp, one of the largest Australian media conglomerates transferred its listing to New York in 2004. Under the US legislation, it is easier for directors, especially founder Rupert Murdoch, to issue a poison pill to fend off a possible bid from John Malone (the next largest shareholder, owning around 18\%) (Source: "Murdoch's Poisson Pill", The Age newspaper, 13th August 2005).
} 


\section{Overview of modelling takeover activity}

Takeover activity tend to fluctuate and cluster in periods of time with high levels of takeover activity often referred to as "merger wave" periods. While this notion is widely acknowledged, there is no corresponding consensus on the statistical characterisation of the waves. Three distinct approaches have been presented in the literature to model time series behaviour of takeover activity.

In one approach, Golbe and White (1993) adopt curve estimation methodology to describe the cyclic pattern of M\&As and argue that sine curve estimation is a "reasonable" way to illustrate takeover activity. However, their method is neither a optimal nor an accurate way to describe takeover time-series behaviour as the actual "peaks" and "troughs" in the sine curve model occur at regular intervals that do not match well with actual merger activity.

Another popular approach is to assume that linear time series models (autoregressive processes) are capable of modelling merger wave behaviour. Shughart and Tollison (1984) investigate both the count and dollar values of annual takeovers for the period 1897-1979, and conclude that merger levels are best characterised by either a white-noise process or a stable first-order autoregressive model. Their results raise doubts about the existence of takeover waves, and indicate that levels of merger activity provide no information beyond their relative frequency. Their findings imply that there is no need to develop predictive models of takeover activity, althoughShughart and Tollison (1984) note that their results may not be conclusive because of the small number of observations in some of their sample periods. Moreover, their data series of merger activity is a compilation of three separate sources with different inclusion criteria which raises doubts whether their data are adequate for their investigation. Chowdhury (1993) improves their work by using higher frequency (quarterly) data with unit root tests, and confirms that the aggregate takeover data series (1973-1987) contains a unit root, and that the change in the merger series is random. One implication of Chowdhury (1993)'s result is that economic variables do not affect the level of merger activity over time. However, as he points out, "various components of the data series do not behave uniformly; the conglomerate merger series appear to be stationary while both the horizontal and the vertical series have a unit root" (Chowdhury, 1993, p. 66).

Barkoulas et al. (2001) argue that the dynamic structure in M\&A activity exhibits a "strongly autocorrelated process". They note that the observation of high and low levels of merger activity over time can be attributed to the presence of dependent or long-memory dynamics. 
They present a model of an autoregressive fractionally integrated moving average (ARFIMA) process which is set with the maximum order allowed in the AR and MA polynomials being three. Gaussian semi-parametric and exact maximum likelihood methods are used to estimate the long-memory or fractional-differencing parameter. The advantage of this method is that it provides insights into the persistence of shocks to the merger time-series.

A number of recent studies have argued that a non-linear model, specifically the two-state Markov switching model developed by Hamilton $(1989)^{9}$ should be used to characterise M\&A activity over time (Town, 1992; Linn and Zhu, 1997; Gartner and Halbheer, 2009). Town (1992) and Linn and Zhu (1997) use the classical approach to make an inference based on the Markov switching model by estimating the model's unknown parameters, then making inferences about the unobserved variables, conditional on the parameter estimates. Gartner and Halbheer (2009), on the other hand, employ a Bayesian framework with Gibbs-sampling techniques that treat both the model parameters and Markov switching state variable as random variables, and conduct inferences on a joint probability distribution of parameters and states rather than on a conditional probability distribution of the classical approach. Of these approaches, the former is preferred as Gartner and Halbheer (2009)'s approach is computationally expensive and the Gibbs sampler may fail to converge, or the variance over different runs may be too large to be statistically meaningful. Furthermore, as this method collapses two variables into one, its predictive power (in terms of predicting unseen waves) could be limited due to the generative information being ignored.

Australian research on modelling takeover wave behaviour is relatively limited. Bishop et al. (1987) and the Bureau of Industry Economics (1990) only casually observe the activity of M\&As by graphing the association between takeover bids and share market performance. Both analyses document a positive relationship between changes in the share market index and the incidence of takeovers. A similar finding is made by Easton (1994) when he uses a simple regression technique to quantify the relationship between share market and takeover activity for the period 1946-1986. All authors conclude that such a relationship provides evidence consistent with the existence of takeover waves, but none provide clear reasons for reaching this conclusion, nor do they acknowledge that a positive relationship between share returns and takeover activity could occur without takeover waves. In short, there is no attempt in these studies to use quantitative statistics to uncover the time-series structure of takeover activity that characterises waves.

\footnotetext{
${ }^{9}$ Apart from its application in takeover time series, Hamilton (1989)'s model has been used to test regime changes in structure of some other financial time-series such as GDP (Hamilton, 1989), interest rates (Hamilton, 1988; Gray, 1996; Li and Xu, 2009), foreign exchange rates (Engel and Hamilton, 1990), inflation (Evans and Wachtel, 1993), stock returns of takeover targets (Gelman and Wilfling, 2009), and stock market returns (Wang and Theobald, 2008).
} 
To fill this gap, Kendig (1997) applies Hamilton (1989)'s approach to Australian merger data with a modification to the first-order autoregressive process $(\mathrm{AR}(1))$ where a Poisson distribution is used in place of a Gaussian distribution ${ }^{10}$ because merger data are positive and take discrete values. However, as discrete values of the observations can be accounted for by negligible quantization noise in a standard model, they need not be a point of concern. In addition, there are several shortcomings in Kendig (1997)'s methodology. First, being an AR modelling approach, it is still unable to capture other characteristics of a general non-linear time series model which can be more accurately described by a general autoregressive moving average (ARMA) process. Second, the underlying assumption of the two-state Markov switching regime is that a higher mean and higher variance would be observed in a wave state than in a normal state, while the Poisson distribution assumes that the mean and variance of a Markov state are equal which makes it potentially too restrictive when characterising wave behaviour. As a result, Duong and Izan (2012) propose to utilise the Gaussian distribution and extend the AR(1) processes by using more general ARMA modelling. They use Kim (1994)'s methodology which combines the State-Space model with Hamilton (1989)'s Markov switching model in order to cover more generalised time series. In their approach, a more general ARMA modelling is used, with the AR approach being only a special case of the proposed ARMA approach. By using the Kalman filter to track the variation of the parameters in the State-Space model, they can obtain an approximate estimation of the Markov state and model the time-series behaviour.

In summary, the literature evidences the divergence on how to describe "merger waves" in a time series context. In one approach, merger waves do not exist as M\&A activity is considered random and hence unpredictable (Chowdhury, 1993). In another, merger time series can be captured by a linear process (e.g., Shughart and Tollison, 1984; Barkoulas et al., 2001), or by a non-linear two-state Markov switching model (e.g. Town, 1992; Gartner and Halbheer, 2009; Duong and Izan, 2012). The latter approach is preferable in this analysis since the existence of merger waves is quite obvious in recent literature (e.g. Rhodes-Kropf and Viswanathan, 2004; Harford, 2005; Banal-Estanol et al., 2010) and the initial analysis of Australian takeover data strongly rejects a linear structure. The rejection of AR models suggests that the time series of M\&A activity may be best described by non-linear models. As Australian takeover time series display a clear difference between periods of high-level and low-level activity, this may be traced to structural shifts in the mean of the takeover series. Therefore, the two-state Markov switching-regime model, in which there are two states with different means and variances, to characterise the wave behaviour of merger activity is reviewed in this paper.

\footnotetext{
${ }^{10}$ At each state in Hamilton (1989)'s two-state Markov switching model, the time-series behaviour is described by an AR process. The original approach by Hamilton (1989) is formulated for a Gaussian case, i.e. the noise term is considered Gaussian.
} 


\section{Takeover Data}

This analysis is based on the dataset of Duong and Izan (2012). It incorporates all takeover announcements for Australian listed targets, covers the period from January 1972 to December 2004 and comes from three different sources, but with same inclusion criteria. The first is Bishop et al. (1987)'s study ${ }^{11}$ which covers takeover information between January 1972 and June 1985. The second is hand-collected data from the Australian Financial Review (AFR) ${ }^{12}$ covering the period from early June 1985 to June 1995. The third source comes from Thompson Financial's Securities Data Company (SDC) Platinum database, which contains takeover information from early 1981 to December 2004.

Data from each source are combined to form the time series of takeover bids. Any bid appearing in only one source is added to the final sample. Any bid appearing in multiple sources is checked to ensure agreement on appropriate offer details. The reference date for takeover activity is always taken as the announcement date of the bid. In total there were 5,407 takeover bids announced for ASX-listed targets during the period 1972-2004. Table 1 documents the number of Australian takeover bids identified each year from each of the three data sources. It shows that the level of Australian takeover activity fluctuates over time with clusters in particular periods. An Augmented Dickey-Fuller test is conducted to test for unit roots in the time series of annual takeover data. The test is run with the combination of constant plus time-trend and the null hypothesis is rejected at a $99 \%$ confidence level. In the other words, the time series of annual takeover data is stationary.

[Insert Table 1]

\section{Takeover waves models}

\section{A Gaussian Markov switching AR(1) model}

Hamilton (1989) proposes that a two-state Markov switching approach can well describe the time series of financial or macro-economic indicators if the process is subject to discrete shifts in regime. These shifts, which are governed by the outcome of a Markov process, are illustrated by a large, discrete and unsustainable increase in the mean and variance of the time series, making it non-linear. At each state (a wave state and a non-wave (or normal) state), the time-series behaviour is described by a linear ARMA model. The original approach by Hamilton is formulated for a Gaussian case: that is, the noise term is considered Gaussian. This approach is also valid for AR processes, which are a special case of a more general ARMA framework.

\footnotetext{
${ }^{11}$ The Centre of Independent Studies granted access to their data file, and Dr. Simmons (Australian Graduate School of Management) kindly provided an electronic copy of the database. Their assistance is gratefully acknowledged.

${ }^{12}$ Data were collected for a research project of Professor da Silva Rosa (The University of Western Australia).
} 
Since takeover time series are observed to have "peaks" and "troughs", many researchers (e.g. Town, 1992; Linn and Zhu, 1997) have adopted Hamilton (1989)'s methodology to statistically characterise takeover activity. The two-state Hamilton's Gaussian Markov switching model for $\mathrm{AR}(1)$ process can be mathematically represented by the following equation:

$$
y_{t}-\mu_{S_{t}}=\phi\left(y_{t-1}-\mu_{S_{t-1}}\right)+e_{t}
$$

where

- $y_{t}$ is the number of takeover bids occurred in year $t$

- $e_{t}$ is the error term which is normal, independent and identically distributed with $\mathrm{E}\left(e_{t}\right)=$ 0

- $\phi$ is the AR lag coefficient. The two-state Markov-switching process is composed of two distinct $\operatorname{AR}(1)$ processes which have unequal intercepts but equal lag coefficients.

- $S_{t}$ can take a value of 0 (non-wave or normal state) or 1 (wave state) and denotes the unobservable state at time $t$ in the system

$$
\left\{\begin{array}{lll}
\text { If } & S_{t}=1: & \mu_{S_{t}}=\mu_{1}, e_{t} \sim \mathcal{N}\left(0, \sigma_{1}^{2}\right) \\
\text { If } & S_{t}=0: & \mu_{S_{t}}=\mu_{0}, e_{t} \sim \mathcal{N}\left(0, \sigma_{0}^{2}\right) \\
\text { where } & \mu_{1}>\mu_{0}, & \sigma_{1}>\sigma_{0}
\end{array}\right.
$$

- $\mu_{S_{t}}$ is the mean value of the state $S_{t}$

The state in the system, $S_{t}$, can be parameterised as a first-order Markov process with constant transition probabilities. This implies that the likelihood of the state being in state 0 or 1 depends upon what the state was in the previous period. In the system, there are two other parameters, $p_{00}$ and $p_{11}$, which represent the probability of remaining in a normal state and the probability of being in a wave state in the next period, respectively.

$$
\begin{aligned}
& \operatorname{Prob}\left[S_{t}=1 \mid S_{t-1}=1\right]=p_{11} \\
& \operatorname{Prob}\left[S_{t}=0 \mid S_{t-1}=1\right]=1-p_{11} \\
& \operatorname{Prob}\left[S_{t}=0 \mid S_{t-1}=0\right]=p_{00} \\
& \operatorname{Prob}\left[S_{t}=1 \mid S_{t-1}=0\right]=1-p_{00}
\end{aligned}
$$

If $\mathrm{P}$ is denoted as the probability transition matrix for the two-state process, $\mathrm{P}$ can be represented as:

$$
P=\left[\begin{array}{ll}
p_{00} & 1-p_{00} \\
1-p_{11} & p_{11}
\end{array}\right]
$$




\section{B Poisson Markov switching AR(1) model}

Kendig (1997) modifies Hamilton's AR(1) process by replacing the Gaussian distribution with a Poisson distribution for the conceptual reason that merger data are positive and take discrete values. The two-state Kendig's Poisson Markov switching model for the AR(1) process can be represented by the following system:

$$
\begin{gathered}
y_{t} \sim \operatorname{Pn}\left(\lambda_{t}\right) \\
\left\{\begin{array}{lll}
\text { If } \quad S_{t}=1: & \lambda_{t}=\alpha_{1}+\phi y_{t-1} \\
\text { If } & S_{t}=0: & \lambda_{t}=\alpha_{0}+\phi y_{t-1}
\end{array}\right.
\end{gathered}
$$

where $\alpha_{1}>\alpha_{0}$. The parameter $\phi$ indicates persistence in a particular state.

\section{State-Space Markov switching ARMA (1,1) model}

The assumption of equal mean and variance under the Poisson distribution is a disadvantage of Kendig (1997)'s approach. It is highly restrictive and the underlying approach may not provide a good empirical fit. Kendig's use of the Poisson distribution is because of the positive and discrete values of the merger data. This should not be of great concern in the analysis of Duong and Izan (2012) as the discrete values of the observations can be accounted for by negligible quantisation noise in a standard model. It is believed that the two-state Markov switching model alone does not optimise wave locality and may not be sufficient to describe transient behaviour. Consequently, Duong and Izan (2012) propose a model that uses the procedure described in Kim (1994) to analyse the time-series behaviour of merger activity and verify the existence and extent of merger waves ${ }^{13}$ as Hamilton (1989)'s approach was formulated for AR processes and it cannot be easily modified to accommodate ARMA processes. The two-state Markov switching-regime model for ARMA(1,1) process of Duong and Izan (2012) can be represented by the equation:

$$
y_{t}-\mu_{S_{t}}=\phi\left(y_{t-1}-\mu_{S_{t-1}}\right)+e_{t}+\gamma e_{t-1}
$$

All parameters are the same as those defined in the Gaussian Markov switching model AR(1) (Section A), except for the new parameter $\gamma$, the MA lag coefficient which is identical in both wave state and normal state. The above equation could be expressed in the State-Space form:

$$
\left\{\begin{aligned}
y_{t} & =\mathbf{H} \boldsymbol{\beta}_{t}+\mu_{S_{t}} \\
\boldsymbol{\beta}_{t} & =\mathbf{F} \boldsymbol{\beta}_{t-1}+\mathbf{v}_{t}
\end{aligned}\right.
$$

with the subscript $S_{t}$ referring to Markov state-dependent quantities:

$$
\mathbf{H}=\left[\begin{array}{ll}
1 & \gamma
\end{array}\right]
$$

\footnotetext{
${ }^{13} \mathrm{Kim}$ (1994)'s algorithm is an extension of Hamilton (1989) approach.
} 


$$
\begin{gathered}
\mathbf{F}=\left[\begin{array}{ll}
\phi & 0 \\
1 & 0
\end{array}\right] \\
\mathbf{v}_{t}=\left[\begin{array}{l}
e_{t} \\
0
\end{array}\right] \\
e_{t} \sim \mathcal{N}\left(0, \sigma_{S_{t}}^{2}\right)
\end{gathered}
$$

The State-Space Markov switching model ARMA (1,1) of Duong and Izan (2012) can be reduced to the Gaussian Markov switching model $\operatorname{AR}(1)$ (Section A) by setting $\gamma=0$, hence, it is clearly more general.

\section{Wave identification}

Following the current literature, the high mean, high variance regime is classified as the "wave" period, and the low mean, low variance regime as the "non-wave" (normal) period. In all three models, the probability of being in a wave state, $\operatorname{Pr}\left[S_{t}=1 \mid \Psi_{t}\right]$ where $\Psi_{t}=\left[y_{0}, \ldots, y_{t}\right]$, is determined. ${ }^{14}$ Consistent with previous studies, merger wave periods are identified when $\operatorname{Pr}$ $\left[S_{t}=1 \mid \Psi_{t}\right] \geq 0.5$.

\section{Model Selection}

This section sets out the analysis to determine the "best" model from the three described above. The assessment of all three models is based on the Bayesian information criterion (BIC) score, and the ability of each to predict waves and to explain takeover activity in the regression with macro-economic variables.

\section{A Bayesian information criterion}

According to Burnham and Anderson (2002), a good model selection technique will balance goodness of fit with simplicity. Goodness of fit is generally determined using a likelihood ratio approach. The likelihood ratio test is employed by some researchers (e.g. Hamilton and Susmel, 1994) to test the fit of different Markov model specifications. This is possible since their Markov models have consistently adopted the underlying normal distribution. However, in the case being considered here, the candidates for the model selection problem have different model complexity and distributions. ${ }^{15}$ The likelihood ratio test is thus impractical to implement due

\footnotetext{
${ }^{14}$ Estimation procedure is adapted from Hamilton (1989) for Gaussian Markov switching model AR(1), from Kendig (1997) for Poisson Markov switching model AR(1), and from Duong and Izan (2012) for State-Space Markov switching model ARMA $(1,1)$.

${ }^{15}$ Three different Markov switching models are tested in this paper: Gaussian AR(1) (Hamilton, 1989), Poisson AR(1) (Kendig, 1997), and State-Space ARMA(1,1) (Duong and Izan, 2012). The Gaussian (normal) distribution
} 
to the difficulty in obtaining the distribution of the test statistic under the null hypothesis.

The likelihood ratio test is not the only approach for model selection. For the problem of interest, the Bayesian information criterion (BIC) method can cater for varying model complexity and underlying distributions. The method selects the suitable model that gives the minimum score of

$$
\mathrm{BIC}=-2 \ln L+k \ln n
$$

where $\ln L$ is the $\log$ likelihood estimated from each model, $k$ is the number of parameters in the model, and $n$ is the number of observations.

\section{B Future wave prediction}

One of the advantages of the Markov regime switching model, as Hamilton (1989, 1994) have pointed out, is its ability to make inferences about which state is in force for each date $t$ in the sample period. These inferences are in the form of conditional probabilities calculated from the history of the takeover data series and the maximum likelihood estimates of the model's parameters. That is, assuming that the model is correctly specified, the future probabilities of being in the wave state (state 1) or the normal state (state 0) can be predicted using the transition probability matrix implied by equation (2) in the earlier section.

To determine the probability of being a state in $k$ years in the future $(\mathrm{k}=1,2,3, \ldots, \mathrm{n})$, the current state is multiplied by the probability transition matrix:

$$
[\text { Initial state }][\mathrm{P}]^{k}=[\text { Final state }] .
$$

Another important feature of the Markov regime switching model is its ability to calculate the expected duration of the wave and non-wave states from the maximum likelihood parameter estimates. The diagonal elements of the matrix of the transition probabilities (2) contain important information on the expected duration of a state or regime. Given currently in regime $j$, the relevant question is how long, on average, will the regime $j$ last? It can be mathematically derived that the expected duration of regime $j$ is $\left(1-p_{j j}\right)^{-1}$. Conditional on being a normal state (state 0 ), the expected duration of a normal state is $\left(1-p_{00}\right)^{-1}$. The expected duration of being in a wave state is likewise $\left(1-p_{11}\right)^{-1}$. Based on the calculation of expected duration of a wave and non-wave state, and the application of the above transition matrix, the next merger wave can be predicted for each model. A good model is one that forecasts the next wave close to what actually happen in the takeover market.

is used in the first and the third model, while the underlying distribution for the second model is Poisson. 


\section{Regression with macro-economic variables}

Another method of testing the usefulness of a model is to examine how well it does in explaining merger waves after controlling for other influencing effects. Although takeover waves are widely recognised in the literature, previous research on takeover motives has almost exclusively used regression models without accounting for the likelihood of the occurrence of takeover waves. The inclusion of the merger wave probability from a good model in the macro-economic model should better explain the variation in takeover activity if that model performs well in predicting the occurrence of the wave. In other words, the adjusted R-square figure would be higher in a regression that controls for takeover probability, compared with a regression analysis that does not control for takeover waves. Furthermore, the highest adjusted R-square figure would be obtained in the regression when incorporating takeover probability derived from the good model.

A multivariate model is estimated to control for factors other than the wave effect that can also influence the takeover activity. Control variables are based on the previous findings in the literature, which include macro-economic indicators, long-term interest rates and stock market returns. ${ }^{16}$ Macro-economic indicators included in the regression analysis are the growth rates of industrial production $(T I P)$ and of private capital expenditure $(C A E) .{ }^{17}$ The level of longterm interest rate $(I N T)$ (10-year Treasury Bond $)^{18}$ is chosen as proxy for the availability of liquidity in the debt market since the cost of obtaining liquidity via a bond issue or a bank loan should increase if the level of interest rate rises. ${ }^{19}$ In addition to aggregate stock market return $(A O I),{ }^{20}$ one new variable is added to capture industry return. It is chosen to include only the most active industry (i.e. Metals \& Mining industry group ${ }^{21}$ ) to proxy for the in-

\footnotetext{
${ }^{16}$ There is evidence in the US literature that the level of takeover activity is positively related to industrial production, GNP level, and stock price (e.g. Nelson, 1959; Steiner, 1975; Melicher et al., 1983; Golbe and White, 1988) while real interest rates are negatively linked to takeovers (e.g. Melicher et al., 1983; Golbe and White, 1988). The finding of a significantly positive relationship between stock market performance and takeover activity is also present in some Australian empirical studies (e.g. Easton, 1994; Kendig, 1997) and recent theoretical models (Shleifer and Vishny, 2003; Rhodes-Kropf and Viswanathan, 2004). However, Finn and Hodgson (2005), in a study of takeover announcements for ASX-listed targets, challenge this common belief. They conclude that while takeover and stock prices share a common trend, Australian aggregate merger activity is driven by fundamental economic factors rather than by speculative share market activity or managerial optimism. They find that economic shock, proxied by the growth in industrial production, is the main factor to explain Australian M\&A activity.

${ }^{17}$ Data on macro-economic variables are obtained from the Australian Bureau of Statistics.

${ }^{18}$ The annual yields on 10-year Australian treasury bonds are obtained directly from the Reserve Bank of Australia website, and converted to effective quarterly rates.

${ }^{19}$ Using local interest rate clearly can only explain domestic debt market liquidity. However, as foreign bidders do not account for a large proportion of the sample (approximately $22 \%$ ), it is reasonable to assume that their borrowing capacity from foreign markets does not have a strong impact on the results.

${ }^{20}$ The return on ASX All Ordinaries Accumulation Index in excess of the 90-day bank bill rate is a proxy for the aggregate market return.

${ }^{21}$ For the Australian market, the industry classification system was previously based on the ASX scheme which was replaced by Standard \& Poors Global Industry Classification Standard (GICS) in September 2002. Since the sample is from 1980 to 2004, it is essential to reclassify all target companies according to the new GICS standards. For companies with deals announced in the 1990s and later, their financial reports are obtained via Aspect Financial database and they are classified by mapping their business operation to the GICS guide (obtained from the ASX website). For companies whose deals announced in the 1980s, the information is extracted from the
} 
dustry return $\left(I N D_{M}\right)^{22}$ as M\&As tend to cluster around particular industries (Mitchell and Mulherin, 1996; Harford, 2005). Both the aggregate and industry share market performance are included to measure the additional impact for the industry over and above the aggregate market.

In the previous analysis of the time series of number of takeover bids from 1972 to 2004, merger waves are detected only in the 1980s, 1990s and 2000s for all three models (see Figure 1). Since data for some macro-economic variables are only available for periods in the late 1970s, this analysis only examines the influences of macro-economic and financial market variables lagged by one quarter on the current level of takeover activity during the period 1980-2004. Figure 1 shows the probability of being in a wave state when modelling annual time series of the number of Australian takeover bids by all three models: Gaussian AR(1) (Hamilton, 1989), Poisson AR(1) (Kendig, 1997), and State-Space ARMA(1,1) (Duong and Izan, 2012). As quarterly data series are used in the regression, it is assumed that the probability of four quarters in a given year remains the same. The regression model is estimated as follows:

$$
\begin{array}{r}
T A K_{i t}=\alpha+\beta_{1} A O I_{t-1}+\beta_{2} I N D_{M_{t-1}}+\beta_{3} I N T_{t-1}+\beta_{4} T I P_{t-1} \\
+\beta_{5} C A E_{t-1}+\beta_{6} \text { WaveEffect }+\epsilon_{i t}
\end{array}
$$

In the regression, $T A K$ is the number of takeover bids to ASX-listed target companies; AOI, $I N D_{M}, I N T$, TIP and $C A E$ are macro-economic variables defined above. The Wave Effect is measured in two ways: the probability of being in a wave state (Wave Prob.) that derived from each of the three models (see Figure 1); or the dummy variable for being in a wave period (In-wave Dum.), i.e. the wave probability is equal to or greater than 0.5 .

\section{Results}

\section{A BIC and Future wave prediction}

Experiments are conducted for the: Poisson Markov switching AR(1) model, Gaussian Markov switching AR(1) model, and State-Space Markov Switching ARMA(1,1) model using annual data for the number of takeover bids. The maximum-likelihood parameter estimates for each model are presented in Table 2 and clearly indicate that the estimates of mean and variance during waves (wave state) are significantly larger than those in non-wave periods (normal state) in all models. In other words, the periods of high level M\&A activity are also periods of increasing M\&A volatility. The regime shifts are clearly evident by large increases in the means and vari-

business operation section in Jobson's Year Book of Public Companies. It is found that the most active industry is Metals \& Mining (1,069 bids out of 4,570 total bids in the working sample).

${ }^{22}$ The abnormal excess return on the GICS Metals \& Mining industry is derived as the residuals from the regression of this industry excess return (data are obtained from the Share Price and Price Relative (SPPR) database) on the excess return of All Ordinaries Accumulation Index. This ensures that the Metals \& Mining excess return (residuals) is orthogonal to the All Ordinaries Accumulation excess return. 
ances of the series. The estimated parameters in all models are significant. The parameter $\gamma$ is also significant which indicates that the State-Space and Markov switching model of Duong and Izan (2012) offers improvements over the original Hamilton AR processes. Under the Bayesian information criterion (BIC) for model selection, the State-Space ARMA $(1,1)$ approach has the best fit with the lowest BIC score of 346.67 .

[Insert Table 2]

An interesting point is to compare the detected Australian takeover waves with those found by previous studies in other markets. As mentioned earlier, a merger wave is recognised when the probability of being in a wave state is equal to or greater than 0.5. Figure 1 shows merger wave periods for each of the three models in the late 1980s, the early to middle of 1990s, and the early 2000s. There is no wave reported in the 1970s, probably due to the peaks in this decade not being as strong as those in later decades. If there are only two states in the model: wave and non-wave, then the weaker wave in the 1970s is likely to be statistically classified as the normal state. Under the State-Space Markov switching ARMA(1,1) model of Duong and Izan (2012), four waves are identified: the first in the period 1987-1989, the second in the year 1991, the third in the period 1995-1996, and the last in the two years 2003-2004. Four merger waves are detected under the Poisson Markov switching AR(1) model of Kendig (1997) in the following years of 1987-1988, 1991, 1993-1996, 2000 and 2003. The Gaussian Markov switching AR(1) model of Hamilton (1989) identifies similar waves as the Poisson AR(1) model but also recognises the year 1992 as part of the wave in the 1990s. Town (1992) documents a US takeover wave in late 1986, but no wave is found in the 1970s. Linn and Zhu (1997) record a high level of merger activity in the US for the period 1986-1993, but again no wave is found during the 1970s. Gartner and Halbheer (2009) confirm no waves in the 1970s and 1980s for the US market, but evidence a merger peak from late 1995 to 2003. They also study the UK takeover market and find merger waves in 1971-1973, and 1986-1989. The finding of no Australian merger wave in the 1970s is similar to that in previous US studies. The wave in the late 1980s is apparent in all Australian, UK and US studies. ${ }^{23}$ The last two Australian waves in the 1990s and 2000s correspond with waves identified in the US market.

[Insert Figure 1]

The final inference from each of the Markov switching models is on the duration and expected timing of the waves. As pointed out earlier, the expected duration of a normal state is $\left(1-p_{00}\right)^{-1}$, and the expected duration of a wave state is $\left(1-p_{11}\right)^{-1}$. Using figures in the State-Space Markov switching ARMA(1,1) model, it is calculated that the expected duration of a wave state and a normal state equates to 2 and 5.88 years, respectively. The corresponding figures for the Poisson

\footnotetext{
${ }^{23}$ This 1980s wave is apparent in Town (1992) and Linn and Zhu (1997) but not in Gartner and Halbheer (2009).
} 
Markov switching AR(1) model are 1.45 years and 3.03 years, and 1.79 years and 2.5 years for the Gaussian Markov switching AR(1) model. The durations confirm the information supplied by the transition probabilities. Across all three models, the expected duration of a non-wave state is considerably longer than the duration of a wave state, and the dominant state is clearly state 0 (non-wave state).

Under the State-Space Markov switching ARMA(1,1) model, the Australian takeover market, on average, maintains low-level activity for about six years, and then jumps into high-level activity for around two years. These calculations and the application of the transition matrix described in Section B imply that another takeover wave is likely to occur around 2009. Similar analyses reveal that the next takeover wave is probably expected to appear in 2006 under the Poisson Markov switching AR(1) model, or the middle of 2005 under the Gaussian Markov switching AR(1) model. To verify the future wave prediction of each model, all takeover bids for ASXlisted companies after the period of examination, i.e. from 2005 to 2009, are collected. Figure 2 presents the time series of takeover bids for the period 1972-2009 with the identified takeover waves (being vertical lines and bars) of all three models by using 1972-2004 data. It can be seen from Figure 2 that the number of Australian takeover bids substantially dropped in 2005, picked up in 2006 and 2007, and slightly decreased in 2008 before jumping up in 2009. It, hence, appears that the State-Space model of Duong and Izan (2012) predicts the timing of the next takeover wave better than the other two models.

[Insert Figure 2]

\section{B Regression with macro-economic variables}

Panel B of Table 3 presents regression results of the number of takeover bids on macro-economic and financial market variables with and without controlling for merger wave periods. The correlation matrix of variables used in the regressions is shown in Panel A. In Column (1) of Panel B (Table 3), the regression analysis is initially performed without taking into account takeover waves, while the two measures of takeover waves (In-wave Dummy and Wave Prob.) are later added into the regression for each of the three models (Columns (2) to (7)).

[Insert Table 3]

It is clear that higher adjusted R-squares are found in the regressions that control for takeover waves. Across the three models, the highest adjusted R-square figures are obtained when incorporating takeover wave probability derived from the State-Space Markov switching ARMA $(1,1)$ model. When the takeover wave periods (In-wave Dum.) of the State-Space model are incorporated in the regression, on average $62 \%$ of variations in takeover activity can be explained by the regression model, this figure reduces to below $20 \%$ when they are omitted. When the 
takeover wave periods of the Gaussian and Poisson Markov switching model AR(1) are included in the regression, the adjusted R-square figures are approximately $27 \%$ and $33 \%$, respectively. This finding is robust when the measure of takeover waves is changed from the dummy variable (In-wave Dum.) to the actual probability (Wave Prob.) that is derived when modelling the number of takeover bids time series. Columns (3), (5) and (7) of Panel B show that adding the Wave Prob. variable in the regression increases the adjusted R-square to nearly $37 \%, 33 \%$ and $65 \%$ in the case of the Gaussian, Poisson and State-Space models, respectively. In all regressions, the variables that measure merger wave periods (In-way Dum. or Wave Prob.) are highly significant (at the $1 \%$ level) and positively related to the number of takeover bids.

In order to see a more comprehensive picture of the effects of merger waves on takeover bids, the above ordinary least-squares regression is modified to quantile regression with $\tau$ ranging from 0.05 to 0.95 . While the method of least squares results in estimating the conditional mean of the takeover bid variable, quantile regression aims at estimating either the conditional median or other quantiles of this variable. The results from quantile regressions (i.e. running from 5th to 95 th quantiles of the number of takeover bids) are very similar to that of the ordinary least-square regression above. ${ }^{24}$ The wave variables (In-wave Dum. and Wave Prob.) are significantly positive across all quantiles for the Poisson and State-Space model, and from the 25th quantile in the Gaussian model. Within the same quantile, the State-Space model still gives the highest adjusted R-square figure, indicating it provides a best fit. In all three models, the wave variables have larger positive impact on the higher quantile of the number of takeover bids.

The regression analysis in Panel B of Table 3 also reveals that movements in the stock market do not play a significant role in explaining the concentration of takeover activity, but interest rate does. ${ }^{25}$ The coefficients of returns on aggregate market (All Ordinaries Accumulation Index) and industry (Metals \& Mining) are not statistically significant. This finding is consistent with an Australian study by Finn and Hodgson (2005) in which they conclude that takeover and stock prices share a common trend, and that Australian aggregate merger activity is driven by fundamental economic factors rather than by speculative share market activity or managerial optimism. The finding of a significantly negative relationship between interest rate and takeover volume is robust even when the measure of interest rate is changed from long-term (i.e. 10-year Treasury bond) to short-term (proxy by 90 -day bank bill rate).

The relationship between a low interest rate environment and higher aggregate takeover activity

\footnotetext{
${ }^{24}$ The results of quantile regressions are available on request.

${ }^{25}$ Examining each variable separately reveals that interest rate and stock market variables are compliments, not substitutes since their coefficient estimates are different in terms of sign and statistical significance, and the adjusted R-square figures are not the same. Similar results of the effect of interest rate on takeovers are also found in the quantile regression analysis.
} 
is consistent with studies on capital liquidity in the corporate restructuring literature. Shleifer and Vishny (1992) argue that a higher volume of takeover transactions will occur in a liquid market with high corporate cash flows and few financial constraints. They believe that takeover waves are symptoms of a lower cost of capital, as enhanced liquidity makes debt financing more attractive for firms to finance their acquisitions. ${ }^{26}$ Schlingemann et al. (2002) make a similar argument in their study of divestitures and asset liquidity, showing that firms are more likely to sell corporate assets in the most liquid market. Harford (2005) illustrates that sufficient capital liquidity must be present to accommodate the asset reallocation, and an aggregate merger wave can be explained by a macro-level expansion in liquidity. Martynova and Renneboog (2008), graphically viewing takeover activity across the US, Europe and Asia-Pacific regions, note that merger waves usually coincide with periods of rapid credit expansion. In a study of unlisted US companies that are subject to a takeover offer, Officer (2007) finds strong support for a relationship between acquisition discounts and aggregate debt market liquidity; acquisition discounts for unlisted targets are significantly higher when debt capital is difficult or relatively more expensive to obtain. He states "Selling part or the whole of an unlisted firm is a last-resort source of liquidity for owners that need sources of cash when borrowing additional funds is unappealing" (Officer, 2007, p. 597). The results of his study imply that firms should not sell their unlisted assets, as part (divestiture) or whole (M\&A), when the aggregate debt market liquidity condition is tighter since the sale price will be discounted more heavily.

The negative sign on the interest rate coefficient can be explained intuitively. Interest rate reflects inflationary expectations. ${ }^{27}$ Higher inflation rate associated with higher interest rate is a negative signal to businesses. Higher inflation is generally associated with an increase in business uncertainty, a loss of confidence and a decrease in profit margins, all of which tend to dampen expectations and merger activity. It is asserted that the level of interest rate can suitably be used as a proxy for the availability of liquidity in the debt market since the cost of obtaining liquidity via a bond issue or a bank loan should increase if the level of interest rate increases. A low interest rate environment provides a low cost of debt and reduces financial constraints in the market, and subsequently increases the volume of takeover transactions. This finding is consistent with recent developments in the Australian takeover market which has seen an unprecedented increase in M\&A activity funded by private equity. ${ }^{28}$ According to the Reserve

\footnotetext{
${ }^{26}$ In the sample, cash bids are dominant and account for approximately $70 \%$ of the total bids

${ }^{27}$ The argument for a positive relationship between inflation and interest rate has been generally supported by economists. For example, Rory Robertson, an economist at Macquarie Bank, recently mentioned that "There's a pattern here. Over the past 18 months the Reserve Bank has had four disturbing inflationary reports and two comforting inflationary reports. Each of the disturbing inflationary reports was followed by a rate hike, so the pattern has been if there was a disturbing inflationary report at the end of October then you would be right to expect a move in November." Cited in "RBA hints at further rates rise" by S. Long, ABC News, 13 August 2007, http://www.abc.net.au/news/stories/2007/08/13/2004030.htm?section=business.

${ }^{28}$ For examples, foreign private equity firms aimed massive takeover bids at some big Australian companies like Qantas and Coles in 2007.
} 
Bank of Australia (RBA), the staggering rate of growth in this investment sector is driven by "unusual circumstances, including a very low cost of debt". ${ }^{29}$ The RBA also believes that the current drop in liquidity caused by the prospect of higher interest rates is likely to result in far few takeover deals going ahead. ${ }^{30}$

\section{Summary - Model selection}

The analyses in this paper reveal that the State-Space Markov switching ARMA(1,1) model is "better" than the Gaussian Markov switching AR(1) model and the Poisson Markov switching $\mathrm{AR}(1)$ model. It has the lowest BIC score, highest adjusted R-square in the regression with macro-economic variables, and is able to forecast the next wave more closely to what happen in the market.

\section{Robustness}

The previous sections report the regression results when analysing the time series of the number of takeover bids. Since the number of companies listed on the ASX changes over time, there is a need to account for the growth of companies. The takeover measurement is thus changed from the number of takeover bids to its proportion relative to the number of companies listed on the ASX. ${ }^{31}$ Similar analysis are followed for each of the three models. The estimation and regression results are presented in Table 4 (for the maximum-likelihood parameter estimates of all models), Figure 3 (for the wave state probabilities of the proportion of takeover bids time series), and Table 5 (for the predictive regressions of the proportion of takeover bids). As evidenced in Tables 4 and 5, the results are very similar with the State-Space Markov switching model having smallest BIC score (Table 4) and biggest adjusted R-square in the macro-economic variables regressions (Table 5 ).

[Insert Table 4], [Insert Table 5] and [Insert Figure 3]

Both the Poisson and Gaussian Markov switching AR(1) model detect two waves (in the years 1991 and 2003), while an additional wave in the year 1988 is also recognised under the StateSpace Markov switching ARMA(1,1) model (Figure 3). Based on the formulae in Section B, the expected duration of wave and non-wave states are calculated for each model. They are 1.1 and 10 years, respectively, for the Poisson model, 1.08 and 14.29 years for the Gaussian model, and

\footnotetext{
${ }^{29}$ A Senate Committee was inquiry into private equity investment in Australia, in the wake of the failed $\$ 11$ billion private equity bid for Qantas. Citation is from Mr. Battellino's (RBA deputy governor) speech when he gave evidence to the Senate inquiry on 25th July 2007 in Sydney.

${ }^{30}$ E. Alberici, "Private Equity Value Plummeting, Inquiry Hears", 25th July 2007, ABC news, http://www.abc.net.au/news/stories/2007/07/25/1988452.

${ }^{31}$ The number of companies listed on ASX is obtained from combining two sources: Finn and Hodgson (2005) (for the period 1980-1996) and Share Price and Price Relative database (SPPR) (for the period 1997-2004).
} 
1.24 and 5.26 years for the State-Space model. The original dataset is also expanded from 2005 to 2009 to see how well each model predicts the next wave. Figure 4 shows the time series of the proportion of takeover bids for the period 1972-2009 with the detected takeover waves (being vertical lines) of all three models by using 1972-2004 data. The calculation of durations together with the transition matrix in Section B imply that another takeover wave may probably happen around 2013 under the Poisson model, or 2017 under the Gaussian model, or from the end of 2008 to early 2009 under the State-Space model. It is currently unable to see the future waves for the first two models. However, as can be seen from Figure 4, the peak in the year 2009 is aligned with the wave prediction of the State-Space model.

[Insert Figure 4]

In summary, the findings remain unchanged when the measure of takeover bids is modified and presented as a proportion relative to ASX-listed companies. The State-Space Markov switching ARMA(1,1) model of Duong and Izan (2012) is still the best choice.

\section{Conclusions}

In this study, the univariate behaviour of Australian takeover time series is reviewed by using a recent and comprehensive data set (covering all takeover bids to ASX-listed targets from 1972 to 2004). Initial analysis of the data has revealed that linear models do not adequately capture the structure of takeover data, and that aggregate merger data are best operationalised by a non-linear, two-state Markov switching model. Takeover activity alternates between two states: high mean and high variance state (wave state), and low mean and low variance state (normal state). The advantages of using a Markov regime switching model include the possibility of drawing inferences about future probabilities of being in a wave state or a normal state, and the possibility of estimating the expected duration of each state.

Three Markov switching models, the Gaussian AR(1) (Hamilton, 1989), Poisson AR(1) (Kendig, 1997), and State-Space ARMA(1,1) (Duong and Izan, 2012), are under examination to determine which is the best model of merger waves in the Australian market. Based on a number of criteria, this study finds that the State-Space Markov switching ARMA(1,1) model of Duong and Izan (2012) provides the best capture of Australian takeover time series. This model gives a best fit based on the Bayesian information criterion (BIC), i.e., it has the lowest BIC score. In addition, it is better at explaining variations in takeover activity than the other two models when takeover wave periods (and takeover wave probability) are incorporated into the regression analysis of takeover motives. In addition, this model predicts a takeover wave in 2009 which has subsequently been proven correct - there was a significant increase in takeover activity in the 
Australian market that year. This result is unchanged when the measure of takeover activity is swapped from the number of takeover bids to the proportion of takeover bids relative to the number of ASX-listed companies. 


\section{References}

Andrade, G., Mitchell, M. and Stafford, E. (2001), 'New Evidence and Perspectives on Mergers', Journal of Economic Perspectives 15(2), 103-120.

Armour, J. and Skeel, D. (2007), 'Who Writes the Rules for Hostile Takeovers and Why? The Peculiar Divergence of US and UK Takeover Regulation', Georgetown Law Journal 95(6), 17271794 .

Banal-Estanol, A., Heudhues, P., Nitsche, R. and Seldeslachts, J. (2010), 'Screening and Merger Activity', Journal of Industrial Economics 58(4), 794-817.

Barkoulas, J. T., Baum, C. F. and Chakraborty, A. (2001), 'Waves and Persistence in Merger and Acquisition Activity', Economics Letters 70(2), 237-243.

Bishop, S., Dodd, P. and Officer, R. R. (1987), 'Australian Takeovers: the Evidence 1972-1985', The Centre for Independent Studies .

Brock, W., Dechert, D., Scheikeman, J. and LeBaron, B. (1996), 'A Test for Independence Based on the Correlation Dimension', Econometric Reviews 15, 197-235.

Bureau of Industry Economics (1990), Mergers and Acquisitions, Research Report No 36, Canberra, Australia.

Burnham, K. and Anderson, P. (2002), Model Selection and Multi-model Inference: A Practical Information-theoretic Approach, 2nd Edition, New York, Springer.

Chowdhury, A. R. (1993), 'Univariate Time-series Behaviour of Merger Activity and its Various Components in the United States', Applied Financial Economics 3(1), 61-66.

Dignam, A. and Galanis, M. (2004), 'Australia Inside-out: The Corporate Governance System of the Australian Listed Market', Melbourne University Law Review 21(3), 623-653.

Duchin, R. and Schmidt, B. (2013), 'Riding the Merger Wave: Uncertainty, Reduced Monitoring, and Bad Acquisitions', Journal of Financial Economics 107(1), 69-88.

Duong, L. and Izan, H. Y. (2012), 'Consequences of Riding Takeover Waves', International Review of Finance 12(4), 399-434.

Easton, S. (1994), 'Takeover Activity and Share Returns in Australia', Applied Economic Letters $\mathbf{1}(4), 66-68$.

Engel, C. and Hamilton, J. (1990), 'Long Swings in the Dollar: Are They in the Data and Do Markets Know It?', American Economic Review 80(4), 689-713.

Evans, M. and Wachtel, P. (1993), 'Inflation Regimes and the Sources of Inflation Uncertainty', Journal of Money, Credit and Banking 25(3), 475-511.

Finn, F. and Hodgson, A. (2005), 'Takeover Activity in Australia: Endogenous and Exogenous Influences', Accounting and Finance 45(3), 375-394.

Gartner, D. and Halbheer, D. (2009), 'Are There Waves in Merger Activity After All?', International Journal of Industrial Organization 27(6), 708-718.

Gelman, S. and Wilfling, B. (2009), 'Markov-switching in Target Stocks during Takeover Bids', Journal of Empirical Finance 16(5), 745-758. 
Golbe, D. L. and White, L. J. (1988), Merges and Acquisitions in the U.S Economy: An Aggregate and Historical Overview, In A. J. Auerback (ed.), Mergers and Acquisitions, University of Chicago Press, Chicago, 25-47.

Golbe, D. L. and White, L. J. (1993), 'Catch a Wave: The Time Series Behaviour of Mergers', The Review of Economics and Statistics 75(3), 493-499.

Gorton, G., Kahl, M. and Rosen, R. (2009), 'Eat or Be Eaten: A Theory of Mergers and Merger Waves', Journal of Finance 64(3), 1291-1344.

Gray, S. F. (1996), 'Modelling the Conditional Distribution of Interest Rates as a Regimeswitching Process', Journal of Financial Economics 42(1), 27-62.

Gugler, K., Mueller, D. C. and Yurtoglu, B. B. (2006), The Determinants of Merger Waves. WZB - Markets and Politics Working Paper No. SP II 2006-01. Available at SSRN: http://ssrn.com/abstract $=507282$.

Hamilton, J. D. (1988), 'Rational-expectations Econometric Analysis of Changing Regime: An Investigation of The Term Structure of Interest Rate', Journal of Economic Dynamics and Control 12, 385-423.

Hamilton, J. D. (1989), 'A New Approach to the Economic Analysis of Nonstationary Time Series and the Business Cycle', Econometrica 57(2), 357-385.

Hamilton, J. D. (1994), Time Series Analysis, Princeton University Press, Princeton, New Jersey.

Hamilton, J. D. and Susmel, R. (1994), 'Autoregressive Conditional Heteroskedasticity and Changes in Regime', Journal of Econometrics 64(1-2), 307-33.

Harford, J. (2003a), Efficient and Distortional Components to Industry Merger Waves. AFA 2004 San Diego Meetings. Available at SSRN: http://ssrn.com/abstract=388441.

Harford, J. (2003b), 'Takeover Bids and Target Directors' Incentives: The Impact of a Bid on Directors' Wealth and Board Seats', Journal of Financial Economics 69(1), 52-83.

Harford, J. (2005), 'What Drives Merger Waves', Journal of Financial Economics 77(3), 529560 .

Kendig, C. (1997), Takeover Waves: Behaviours, Motives and Consequences, PhD thesis, The University of Melbourne.

Kim, C. (1994), 'Dynamic Linear Models with Markov-Switching', Journal of Econometrics 60(1), 1-22.

Li, H. and Xu, Y. (2009), 'Short Rate Dynamics and Regime Shifts', International Review of Finance 9(3), 211-241.

Linn, S. C. and Zhu, Z. (1997), 'Aggregate Merger Activity: New Evidence on the Wave Hypothesis', Southern Economic Journal 64(1), 130-146.

Ljung, G. M. and Box, G. E. P. (1978), 'On a Measure of Lack of Fit in Time Series Model', Biometrika 65(2), 297-203.

Martynova, M. and Renneboog, L. (2008), 'A Century of Corporate Takeovers: What Have We Learned and Where Do We Stand?', Journal of Banking and Finance 32(10), 2148-2177. 
Melicher, R., Ledolter, J. and D’Antonio, L. (1983), 'A Time Series Analysis of Aggregate Merger Activity', Review of Economics and Statistics 65(3), 423-430.

Mitchell, M. L. and Mulherin, J. (1996), 'The Impact of Industry Shocks on Takeover and Restructuring Activity', Journal of Financial Economics 41(2), 193-229.

Nelson, R. L. (1959), Mergers Movements in American Industry, Princeton University Press, USA.

Officer, M. S. (2007), 'The Price of Corporate Liquidity: Acquisition Discounts for Unlisted Targets', Journal of Financial Economics 83(3), 571-598.

Rhodes-Kropf, M. and Viswanathan, S. (2004), 'Market Valuation and Merger Waves', Journal of Finance 59(6), 2685-2718.

Rosen, R. J. (2006), 'Merger Momentum and Investor Sentiment: The Stock Market Reaction to Merger Announcements', Journal of Business 79(2), 987-1017.

Schlingemann, F. P., Stulz, R. M. and Walkling, R. A. (2002), 'Divestitures and the Liquidity of the Market for Corporate Assets', Journal of Financial Economics 64(1), 117-144.

Shleifer, A. and Vishny, R. W. (1992), 'Liquidation Values and Debt Capacity: A Market Equilibrium Approach', Journal of Finance 47(4), 1343-1366.

Shleifer, A. and Vishny, R. W. (2003), 'Stock Market Driven Acquisitions', Journal of Financial Economics 70(3), 295-311.

Shughart, W. F. and Tollison, R. D. (1984), 'The Random Character of Merger Activity', Rand Journal of Economic 15(4), 500-509.

Steiner, P. O. (1975), Mergers: Motives, Effects, Policies, University of Michigan Press.

Town, R. J. (1992), 'Merger Waves and The Structure of Merger and Acquisition Time-Series', Journal of Applied Econometrics 7(Supplement: Special Issue on Nonlinear Dynamics and Econometrics), S83-S100.

Wang, P. and Theobald, M. (2008), 'Regime-switching Volatility of Six East Asian Emerging Markets', Research in International Business and Finance 22(3), 267-283. 
Table 1: Australian takeover data - number of takeover bids - 1972-2004

\begin{tabular}{|c|c|c|c|c|}
\hline \multirow[b]{2}{*}{ Year } & \multicolumn{4}{|c|}{ Number of takeover bids } \\
\hline & CIS source & AFR source & SDC source & Total sample \\
\hline 1972 & 198 & & & 198 \\
\hline 1973 & 117 & & & 117 \\
\hline 1974 & 65 & & & 65 \\
\hline 1975 & 74 & & & 74 \\
\hline 1976 & 91 & & & 91 \\
\hline 1977 & 80 & & & 80 \\
\hline 1978 & 107 & & & 107 \\
\hline 1979 & 105 & & & 105 \\
\hline 1980 & 132 & & & 132 \\
\hline 1981 & 126 & & 1 & 127 \\
\hline 1982 & 70 & & & 70 \\
\hline 1983 & 94 & & & 94 \\
\hline 1984 & 119 & & 1 & 120 \\
\hline 1985 & 65 & 36 & 2 & 103 \\
\hline 1986 & & 114 & 11 & 125 \\
\hline 1987 & & 175 & 16 & 191 \\
\hline 1988 & & 246 & 36 & 282 \\
\hline 1989 & & 167 & 56 & 223 \\
\hline 1990 & & 94 & 56 & 150 \\
\hline 1991 & & 90 & 139 & 229 \\
\hline 1992 & & 58 & 50 & 108 \\
\hline 1993 & & 58 & 106 & 164 \\
\hline 1994 & & 35 & 148 & 183 \\
\hline 1995 & & 24 & 208 & 232 \\
\hline 1996 & & & 240 & 240 \\
\hline 1997 & & & 181 & 181 \\
\hline 1998 & & & 176 & 176 \\
\hline 1999 & & & 136 & 136 \\
\hline 2000 & & & 182 & 182 \\
\hline 2001 & & & 181 & 181 \\
\hline 2002 & & & 190 & 190 \\
\hline 2003 & & & 438 & 438 \\
\hline 2004 & & & 313 & 313 \\
\hline Total & 1,443 & 1,097 & 2,867 & 5,407 \\
\hline
\end{tabular}

This table presents the number of takeover bids to exchange-listed target companies. Data comes from three different sources: The Centre for Independent Studies (CIS), Australian Financial Review (AFR), and Thompson Financial's Securities Data Company (SDC) Platinum database. 
Table 2: Parameter estimates for different two-state Markov models - number of takeover bids - annual data 1972-2004

\begin{tabular}{|c|c|c|c|}
\hline Parameters & $\begin{array}{l}\text { AR(1) Poisson } \\
\text { Markov Model }\end{array}$ & $\begin{array}{c}\text { AR(1) Gaussian } \\
\text { Markov Model }\end{array}$ & $\begin{array}{c}\operatorname{ARMA}(1,1) \text { State-Space } \\
\text { Markov Model }\end{array}$ \\
\hline$\alpha_{0}$ & $\begin{array}{c}29 \\
(0.0044)\end{array}$ & & \\
\hline$\alpha_{1}$ & $\begin{array}{c}116 \\
(0.0031)\end{array}$ & & \\
\hline$\mu_{0}$ & & $\begin{array}{c}154.33 \\
(0.0019)\end{array}$ & $\begin{array}{c}138.19 \\
(0.0018)\end{array}$ \\
\hline$\mu_{1}$ & & $\begin{array}{l}217.76 \\
(0.0013)\end{array}$ & $\begin{array}{c}201.09 \\
(0.0012)\end{array}$ \\
\hline$\sigma_{0}$ & & $\begin{array}{c}20.22 \\
(0.0111)\end{array}$ & $\begin{array}{c}28.19 \\
(0.0019)\end{array}$ \\
\hline$\sigma_{1}$ & & $\begin{array}{c}72.75 \\
(0.0011)\end{array}$ & $\begin{array}{c}73.36 \\
(0.0017)\end{array}$ \\
\hline$\phi$ & $\begin{array}{c}0.67 \\
(0.001)\end{array}$ & $\begin{array}{c}0.63 \\
(0.001)\end{array}$ & $\begin{array}{c}0.89 \\
(0.001)\end{array}$ \\
\hline$\gamma$ & & & $\begin{array}{c}-0.4 \\
(0.001)\end{array}$ \\
\hline$p_{00}$ & $\begin{array}{c}0.67 \\
(0.0814)\end{array}$ & $\begin{array}{c}0.60 \\
(0.1251)\end{array}$ & $\begin{array}{c}0.83 \\
(0.1718)\end{array}$ \\
\hline$p_{11}$ & $\begin{array}{c}0.31 \\
(0.0403)\end{array}$ & $\begin{array}{c}0.44 \\
(0.1072)\end{array}$ & $\begin{array}{c}0.50 \\
(0.0783)\end{array}$ \\
\hline Log Likelihood & -280.73 & -174.88 & -166.34 \\
\hline BIC & 568.45 & 360.25 & 346.67 \\
\hline
\end{tabular}

This table presents the parameter estimates of three different two-state Markov switching models on the number of takeover bids annual data: AR(1) Poisson Markov model, AR(1) Gaussian Markov model, and ARMA(1,1) State-Space Markov Model. These models can be mathematically represented as:

AR(1) Poisson Markov model: $y_{t} \sim \operatorname{Pn}\left(\lambda_{t}\right)$

$$
\left\{\begin{array}{lll}
\text { If } & S_{t}=1: & \lambda_{t}=\alpha_{1}+\phi y_{t-1} \\
\text { If } & S_{t}=0: & \lambda_{t}=\alpha_{0}+\phi y_{t-1}
\end{array}\right.
$$

$\mathrm{AR}(1)$ Gaussian Markov model: $y_{t}-\mu_{S_{t}}=\phi\left(y_{t-1}-\mu_{S_{t-1}}\right)+e_{t}$

$\operatorname{ARMA}(1,1)$ State-Space Markov Model: $y_{t}-\mu_{S_{t}}=\phi\left(y_{t-1}-\mu_{S_{t-1}}\right)+e_{t}+\gamma e_{t-1}$

Across all models, $S_{t}$ is usded to describe the Markov state at time $t$ and can take a value of 0 (normal state) or 1 (wave state); $\mu_{S_{t}}$ refers to the mean of the state; $p_{00}$ and $p_{11}$ are the probability of remaining in a normal state and a wave state, respectively. Standard errors of the estimates are in brackets. BIC is the score of Bayesian information criterion. 
Table 3: Predictive regressions of the number of takeover bids on explanatory variables lagged by one quarter

Panel A: Correlation matrix of variables

\begin{tabular}{lcccccccc}
\hline & & $\mathbf{( 1 )}$ & $\mathbf{( 2 )}$ & $\mathbf{( 3 )}$ & $\mathbf{( 4 )}$ & $\mathbf{( 5 )}$ & $\mathbf{( 6 )}$ & $\mathbf{( 7 )}$ \\
\hline$T A K_{t}$ & $\mathbf{( 1 )}$ & 1 & & & & & & \\
$A O I_{t-1}$ & $\mathbf{( 2 )}$ & 0.011 & 1 & & & & & \\
$I N D_{M_{t-1}}$ & $\mathbf{( 3 )}$ & 0.137 & -0.044 & 1 & & & & \\
$I N T_{t-1}$ & $\mathbf{( 4 )}$ & -0.445 & -0.078 & -0.134 & 1 & & & \\
$T I P_{t-1}$ & $\mathbf{( 5 )}$ & 0.062 & -0.017 & 0.039 & 0.022 & 1 & & \\
$C A E_{t-1}$ & $\mathbf{( 6 )}$ & -0.389 & 0.058 & -0.019 & 0.552 & -0.089 & 1 & \\
In-wave Dum. (State-space model) & $\mathbf{( 7 )}$ & 0.672 & 0.051 & -0.008 & -0.028 & 0.029 & -0.247 & 1 \\
Wave Prob. (State-space model) & $\mathbf{( 8 )}$ & 0.721 & -0.005 & 0.053 & -0.089 & 0.049 & -0.283 & - \\
\hline
\end{tabular}

Panel B: Regression analysis - Dependent variable: number of takeover bids at time $t$

\begin{tabular}{|c|c|c|c|c|c|c|c|}
\hline & \multirow[b]{2}{*}{$(1)$} & \multicolumn{2}{|c|}{$\begin{array}{l}\text { Gaussian } \\
\operatorname{AR}(1)\end{array}$} & \multicolumn{2}{|c|}{$\begin{array}{c}\text { Poisson } \\
\text { AR }(1)\end{array}$} & \multicolumn{2}{|c|}{$\begin{array}{l}\text { State-Space } \\
\text { ARMA }(1,1)\end{array}$} \\
\hline & & $(2)$ & (3) & $(4)$ & $(5)$ & (6) & $(7)$ \\
\hline Intercept & $\begin{array}{l}68.85^{* * *} \\
{[0.0000]}\end{array}$ & $\begin{array}{c}62.53^{* * *} \\
{[0.0000]}\end{array}$ & $\begin{array}{c}\mathbf{5 5 . 6 1} 1^{* * *} \\
{[0.0000]}\end{array}$ & $\begin{array}{c}61.19^{* * *} \\
{[0.0000]}\end{array}$ & 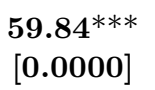 & $\begin{array}{c}63.79^{* * *} \\
{[0.0000]}\end{array}$ & $\begin{array}{l}\mathbf{5 4 . 1 2}^{* * *} \\
{[0.0000]}\end{array}$ \\
\hline$A O I_{t-1}$ & $\begin{array}{c}0.01 \\
{[0.97]}\end{array}$ & $\begin{array}{l}-0.05 \\
{[0.75]}\end{array}$ & $\begin{array}{l}-0.04 \\
{[0.76]}\end{array}$ & $\begin{array}{l}-0.09 \\
{[0.50]}\end{array}$ & $\begin{array}{l}-0.09 \\
{[0.66]}\end{array}$ & $\begin{array}{l}-0.13 \\
{[0.39]}\end{array}$ & $\begin{array}{l}-0.04 \\
{[0.80]}\end{array}$ \\
\hline$I N D_{M_{t-1}}$ & $\begin{array}{c}0.26 \\
{[0.33]}\end{array}$ & $\begin{array}{c}0.22 \\
{[0.33]}\end{array}$ & $\begin{array}{c}0.20 \\
{[0.35]}\end{array}$ & $\begin{array}{c}0.18 \\
{[0.42]}\end{array}$ & $\begin{array}{c}0.17 \\
{[0.51]}\end{array}$ & $\begin{array}{c}0.24 \\
{[0.20]}\end{array}$ & $\begin{array}{c}0.14 \\
{[0.45]}\end{array}$ \\
\hline$I N T_{t-1}$ & $\begin{array}{c}-8.77^{* * *} \\
{[0.01]}\end{array}$ & $\begin{array}{c}-8.60^{* * *} \\
{[0.005]}\end{array}$ & $\begin{array}{c}-9.34^{* * *} \\
{[0.002]}\end{array}$ & $\begin{array}{c}-8.49^{* * *} \\
{[0.005]}\end{array}$ & $\begin{array}{c}-8.12^{* * *} \\
{[0.004]}\end{array}$ & $\begin{array}{c}-11.92^{* * *} \\
{[0.0000]}\end{array}$ & $\begin{array}{c}-10.86^{* * *} \\
{[0.0000]}\end{array}$ \\
\hline$T I P_{t-1}$ & $\begin{array}{c}0.64 \\
{[0.61]}\end{array}$ & $\begin{array}{c}0.25 \\
{[0.83]}\end{array}$ & $\begin{array}{c}0.37 \\
{[0.71]}\end{array}$ & $\begin{array}{l}-0.04 \\
{[0.97]}\end{array}$ & $\begin{array}{l}-0.06 \\
{[0.96]}\end{array}$ & $\begin{array}{c}0.68 \\
{[0.43]}\end{array}$ & $\begin{array}{c}0.51 \\
{[0.54]}\end{array}$ \\
\hline$C A E_{t-1}$ & $\begin{array}{c}-3.53^{*} \\
{[0.06]}\end{array}$ & $\begin{array}{l}-2.12 \\
{[0.15]}\end{array}$ & $\begin{array}{l}-1.41 \\
{[0.33]}\end{array}$ & $\begin{array}{l}-1.93 \\
{[0.18]}\end{array}$ & $\begin{array}{l}-1.88 \\
{[0.29]}\end{array}$ & $\begin{array}{c}0.43 \\
{[0.75]}\end{array}$ & $\begin{array}{c}0.51 \\
{[0.69]}\end{array}$ \\
\hline In-wave Dum. & & $\begin{array}{c}13.01^{* * *} \\
{[0.003]}\end{array}$ & & $\begin{array}{l}17.61^{* * *} \\
{[0.0001]}\end{array}$ & & $\begin{array}{l}31.32^{* * *} \\
{[0.0000]}\end{array}$ & \\
\hline Wave Prob. & & & $\begin{array}{l}28.23^{* * *} \\
{[0.0000]}\end{array}$ & & $\begin{array}{l}18.43^{* * *} \\
{[0.0000]}\end{array}$ & & $\begin{array}{l}49.84^{* * *} \\
{[0.0000]}\end{array}$ \\
\hline Adj. $R^{2}(\%)$ & 19.73 & 26.91 & 36.81 & 33.11 & 33.26 & 62.27 & 64.93 \\
\hline No. of obs & 100 & 100 & 100 & 100 & 100 & 100 & 100 \\
\hline
\end{tabular}

Panel A of the table shows the correlation matrix of variables used in the regression analysis. Pearson correlation is used in measuring the relationship between two quantitative variables; point-biserial correlation is used when correlating a continuous variable with a dummy variable. Panel B presents the results from forecasting the number of takeover bids in quarter $t$ using all macro-economic and financial market variables lagged by one quarter. TAK is the number of takeover bids to ASX-listed target companies. Wave Prob. is the time series of the probability of being in a wave state. In-wave Dum. is a binary variable coded as one if the probability of being in a wave state is equal or greater than 0.5. AOI is excess returns of All Ordinaries Accumulation Index; $I N D_{M}$ is excess returns on Metals \& Mining industry (orthogonal index), computed as the residuals from the regression of this industry excess return on the excess return of All Ordinaries Accumulation Index; INT is 10-year Government Bond rate; TIP and CAE represent the growth rate of total industrial production and private new capital expenditure. The sample period is from 1980 to 2004 (quarterly series). $p$-values appear in parentheses below the parameter estimates. Bold figures indicate that the coefficients are significant at $10 \%$ or better. $*, * *, * * *$ indicate statistical significance at the $10 \%, 5 \%$ or $1 \%$ level. 
Table 4: Parameter estimates for different two-state Markov models - proportion of takeover bids (to number of listed companies) - annual data 1972-2004

\begin{tabular}{|c|c|c|c|}
\hline Parameters & $\begin{array}{l}\text { AR(1) Poisson } \\
\text { Markov Model }\end{array}$ & $\begin{array}{l}\text { AR(1) Gaussian } \\
\text { Markov Model }\end{array}$ & $\begin{array}{c}\text { ARMA }(1,1) \text { State-Space } \\
\text { Markov Model }\end{array}$ \\
\hline$\alpha_{0}$ & $\begin{array}{c}5 \\
(0.0089)\end{array}$ & & \\
\hline$\alpha_{1}$ & $\begin{array}{c}20 \\
(0.0357)\end{array}$ & & \\
\hline$\mu_{0}$ & & $\begin{array}{c}11.37 \\
(0.0179)\end{array}$ & $\begin{array}{c}13.17 \\
(0.0016)\end{array}$ \\
\hline$\mu_{1}$ & & $\begin{array}{c}19.09 \\
(0.0489)\end{array}$ & $\begin{array}{c}17.05 \\
(0.0017)\end{array}$ \\
\hline$\sigma_{0}$ & & $\begin{array}{c}2.64 \\
(0.0067)\end{array}$ & $\begin{array}{c}1.32 \\
(0.0076)\end{array}$ \\
\hline$\sigma_{1}$ & & $\begin{array}{c}7.75 \\
(0.0011)\end{array}$ & $\begin{array}{c}5.72 \\
(0.0012)\end{array}$ \\
\hline$\phi$ & $\begin{array}{c}0.1 \\
(0.001)\end{array}$ & $\begin{array}{c}0.63 \\
(0.001)\end{array}$ & $\begin{array}{c}0.73 \\
(0.001)\end{array}$ \\
\hline$\gamma$ & & & $\begin{array}{c}0.08 \\
(0.001)\end{array}$ \\
\hline$p_{00}$ & $\begin{array}{c}0.9 \\
(0.1861)\end{array}$ & $\begin{array}{c}0.93 \\
(0.3285)\end{array}$ & $\begin{array}{c}0.81 \\
(0.0187)\end{array}$ \\
\hline$p_{11}$ & $\begin{array}{c}0.1 \\
(0.0574)\end{array}$ & $\begin{array}{c}0.07 \\
(0.0288)\end{array}$ & $\begin{array}{c}0.19 \\
(0.0185)\end{array}$ \\
\hline Log Likelihood & -88.62 & -86.96 & -84.01 \\
\hline $\mathrm{BIC}$ & 184.17 & 184.31 & 181.88 \\
\hline
\end{tabular}

This table presents parameter estimates of three different two-state Markov switching models on the proportion of takeover bids (to the number of ASX-listed companies) annual data: AR(1) Poisson Markov model, AR(1) Gaussian Markov model, and ARMA(1,1) State-Space Markov Model. These models can be mathematically represented as:

AR(1) Poisson Markov model: $y_{t} \sim \operatorname{Pn}\left(\lambda_{t}\right)$

$$
\left\{\begin{array}{lll}
\text { If } & S_{t}=1: & \lambda_{t}=\alpha_{1}+\phi y_{t-1} \\
\text { If } & S_{t}=0: & \lambda_{t}=\alpha_{0}+\phi y_{t-1}
\end{array}\right.
$$

$\operatorname{AR}(1)$ Gaussian Markov model: $y_{t}-\mu_{S_{t}}=\phi\left(y_{t-1}-\mu_{S_{t-1}}\right)+e_{t}$

$\operatorname{ARMA}(1,1)$ State-Space Markov Model: $y_{t}-\mu_{S_{t}}=\phi\left(y_{t-1}-\mu_{S_{t-1}}\right)+e_{t}+\gamma e_{t-1}$

Across all models, $S_{t}$ is used to describe the Markov state at time $t$ and can take a value of 0 (normal state) or 1 (wave state); $\mu_{S_{t}}$ refers to the mean of the state; $p_{00}$ and $p_{11}$ are the probability of remaining in a normal state and a wave state, respectively. Standard errors of the estimates are in brackets. BIC is the score of Bayesian information criterion. 
Table 5: Predictive regressions of proportion of takeover bids (to number of listed companies) on explanatory variables lagged by one quarter

Panel A: Correlation matrix of variables

\begin{tabular}{lcccccccc}
\hline & & $\mathbf{( 1 )}$ & $\mathbf{( 2 )}$ & $\mathbf{( 3 )}$ & $\mathbf{( 4 )}$ & $\mathbf{( 5 )}$ & $\mathbf{( 6 )}$ & $\mathbf{( 7 )}$ \\
\hline$\% T A K_{t}$ & $\mathbf{( 1 )}$ & 1 & & & & & & \\
$A O I_{t-1}$ & $\mathbf{( 2 )}$ & 0.042 & 1 & & & & & \\
$I N D_{M_{t-1}}$ & $\mathbf{( 3 )}$ & 0.101 & -0.044 & 1 & & & & \\
$I N T_{t-1}$ & $\mathbf{( 4 )}$ & -0.357 & -0.078 & -0.134 & 1 & & & \\
$T I P_{t-1}$ & $\mathbf{( 5 )}$ & 0.075 & -0.017 & 0.039 & 0.022 & 1 & & \\
$C A E_{t-1}$ & $\mathbf{( 6 )}$ & -0.362 & 0.058 & -0.019 & 0.552 & -0.089 & 1 & \\
In-wave Dum. (State-space model) & $\mathbf{( 7 )}$ & 0.630 & 0.051 & -0.008 & -0.028 & 0.029 & -0.247 & 1 \\
Wave Prob. (State-space model) & $\mathbf{( 8 )}$ & 0.680 & -0.005 & 0.053 & -0.089 & 0.049 & -0.283 & - \\
\hline
\end{tabular}

Panel B: Regression analysis - Dependent variable: proportion of takeover bids at time $t$

\begin{tabular}{|c|c|c|c|c|c|c|c|}
\hline & \multicolumn{3}{|c|}{$\begin{array}{c}\text { Gaussian } \\
\operatorname{AR}(1)\end{array}$} & \multicolumn{2}{|c|}{$\begin{array}{c}\text { Poisson } \\
\text { AR(1) }\end{array}$} & \multicolumn{2}{|c|}{$\begin{array}{l}\text { State-Space } \\
\text { ARMA }(1,1)\end{array}$} \\
\hline & $(1)$ & $(2)$ & (3) & $(4)$ & $(5)$ & (6) & $(7)$ \\
\hline Intercept & $\begin{array}{l}4.83^{* * *} \\
{[0.0000]}\end{array}$ & $\begin{array}{l}4.38^{* * *} \\
{[0.0000]}\end{array}$ & $\begin{array}{l}4.17^{* * *} \\
{[0.0000]}\end{array}$ & $\begin{array}{l}4.02^{* * * *} \\
{[0.0000]}\end{array}$ & $\begin{array}{l}4.01^{* * *} \\
{[0.0000]}\end{array}$ & $\begin{array}{l}4.55^{* * *} \\
{[0.0000]}\end{array}$ & $\begin{array}{c}3.93^{* * *} \\
{[0.0000]}\end{array}$ \\
\hline$A O I_{t-1}$ & $\begin{array}{c}0.01 \\
{[0.56]}\end{array}$ & $\begin{array}{c}0.01 \\
{[0.63]}\end{array}$ & $\begin{array}{c}0.01 \\
{[0.41]}\end{array}$ & $\begin{array}{c}0.01 \\
{[0.50]}\end{array}$ & $\begin{array}{c}0.01 \\
{[0.57]}\end{array}$ & $\begin{array}{c}0.02^{* *} \\
{[0.04]}\end{array}$ & $\begin{array}{c}0.01 \\
{[0.12]}\end{array}$ \\
\hline$I N D_{M_{t-1}}$ & $\begin{array}{c}0.01 \\
{[0.48]}\end{array}$ & $\begin{array}{c}0.01 \\
{[0.65]}\end{array}$ & $\begin{array}{l}0.003 \\
{[0.81]}\end{array}$ & $\begin{array}{c}0.01 \\
{[0.68]}\end{array}$ & $\begin{array}{c}0.01 \\
{[0.73]}\end{array}$ & $\begin{array}{c}-0.003 \\
{[0.84]}\end{array}$ & $\begin{array}{c}0.0004 \\
{[0.98]}\end{array}$ \\
\hline$I N T_{t-1}$ & $\begin{array}{c}-0.39^{*} \\
{[0.07]}\end{array}$ & $\begin{array}{c}-0.34^{*} \\
{[0.06]}\end{array}$ & $\begin{array}{c}-0.33^{*} \\
{[0.06]}\end{array}$ & $\begin{array}{l}-0.12 \\
{[0.51]}\end{array}$ & $\begin{array}{l}-0.18 \\
{[0.29]}\end{array}$ & $\begin{array}{c}-0.43^{* *} \\
{[0.02]}\end{array}$ & $\begin{array}{c}-0.44^{* *} \\
{[0.01]}\end{array}$ \\
\hline$T I P_{t-1}$ & $\begin{array}{c}0.05 \\
{[0.55]}\end{array}$ & $\begin{array}{c}0.13^{*} \\
{[0.07]}\end{array}$ & $\begin{array}{l}0.12^{*} \\
{[0.08]}\end{array}$ & $\begin{array}{c}0.09 \\
{[0.24]}\end{array}$ & $\begin{array}{l}0.12^{*} \\
{[0.09]}\end{array}$ & $\begin{array}{c}0.08 \\
{[0.26]}\end{array}$ & $\begin{array}{c}0.09 \\
{[0.12]}\end{array}$ \\
\hline$C A E_{t-1}$ & $\begin{array}{c}-0.28^{* *} \\
{[0.02]}\end{array}$ & $\begin{array}{c}-0.19 * \\
{[0.09]}\end{array}$ & $\begin{array}{c}-0.18^{*} \\
{[0.09]}\end{array}$ & $\begin{array}{c}-0.29 * * \\
{[0.01]}\end{array}$ & $\begin{array}{c}-0.23^{* *} \\
{[0.03]}\end{array}$ & $\begin{array}{c}-0.19 * \\
{[0.06]}\end{array}$ & $\begin{array}{l}-0.11 \\
{[0.28]}\end{array}$ \\
\hline In-wave Dum. & & $\begin{array}{l}2.79^{* * *} \\
{[0.0000]}\end{array}$ & & $\begin{array}{c}3.84^{* * *} \\
{[0.0001]}\end{array}$ & & $\begin{array}{l}2.45^{* * *} \\
{[0.0000]}\end{array}$ & \\
\hline Wave Prob. & & & $\begin{array}{c}3.43^{* * *} \\
{[0.0000]}\end{array}$ & & $\begin{array}{c}4.16^{* * *} \\
{[0.0000]}\end{array}$ & & $\begin{array}{l}3.63^{* * *} \\
{[0.0000]}\end{array}$ \\
\hline $\begin{array}{l}\text { Adj. } R^{2}(\%) \\
\text { No. of obs }\end{array}$ & $\begin{array}{c}13.25 \\
100\end{array}$ & $\begin{array}{c}39.26 \\
100\end{array}$ & $\begin{array}{c}46.19 \\
100\end{array}$ & $\begin{array}{c}37.94 \\
100\end{array}$ & $\begin{array}{c}45.49 \\
100\end{array}$ & $\begin{array}{c}42.48 \\
100\end{array}$ & $\begin{array}{c}51.05 \\
100\end{array}$ \\
\hline
\end{tabular}

Panel A of the table shows the correlation matrix of variables used in the regression analysis. Pearson correlation is used in measuring the relationship between two quantitative variables; point-biserial correlation is used when correlating a continuous variable with a dummy variable. Panel B presents the results from forecasting the proportion of takeover bids in quarter $t$ using all macro-economic and financial market variables lagged by one quarter. \%TAK is the percentage of takeover bids to the number of companies listed on the ASX. Wave Prob. is the time series of the probability of being in a wave state. In-wave Dum. is a binary variable coded as one if this probability is equal or greater than 0.5. AOI is excess returns of All Ordinaries Accumulation Index; IND $D_{M}$ is excess returns on Metals \& Mining industry (orthogonal index), computed as the residuals from the regression of this industry excess return on the excess return of All Ordinaries Accumulation Index; INT is 10-year Australian Government Bond rate; TIP and CAE represent the growth rate of total industrial production and private new capital expenditure. The sample period is from 1980 to 2004 (quarterly series). $p$-values appear in parentheses below the parameter estimates. Bold figures indicate that the coefficients are significant at $10 \%$ or better. *, **, $* * *$ indicate statistical significance at the $10 \%, 5 \%$ or $1 \%$ level. 

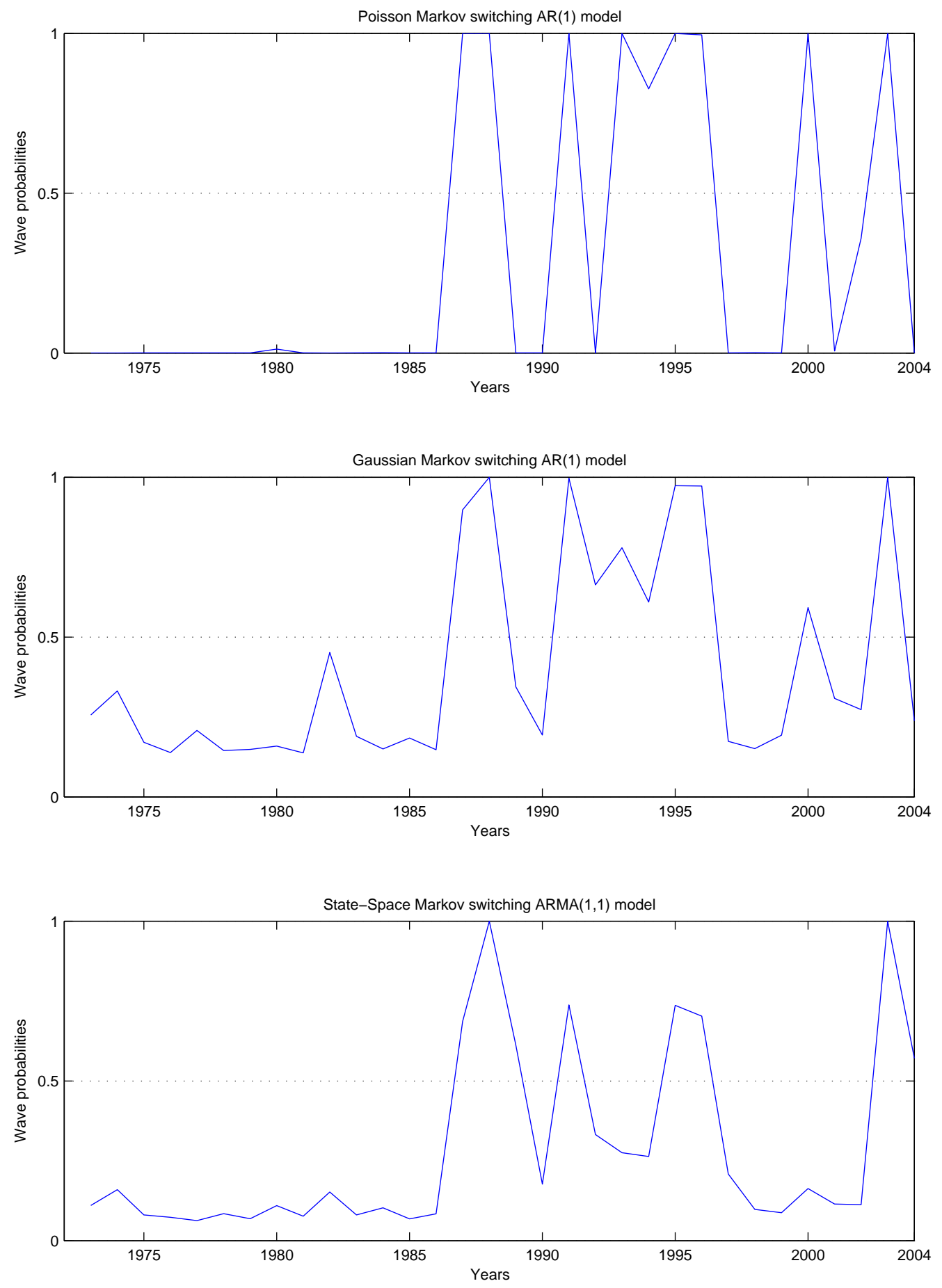

Figure 1: Number of takeover bids - annual data from 1972-2004 - The probability of the takeover process being in wave state across different Markov switching models. 

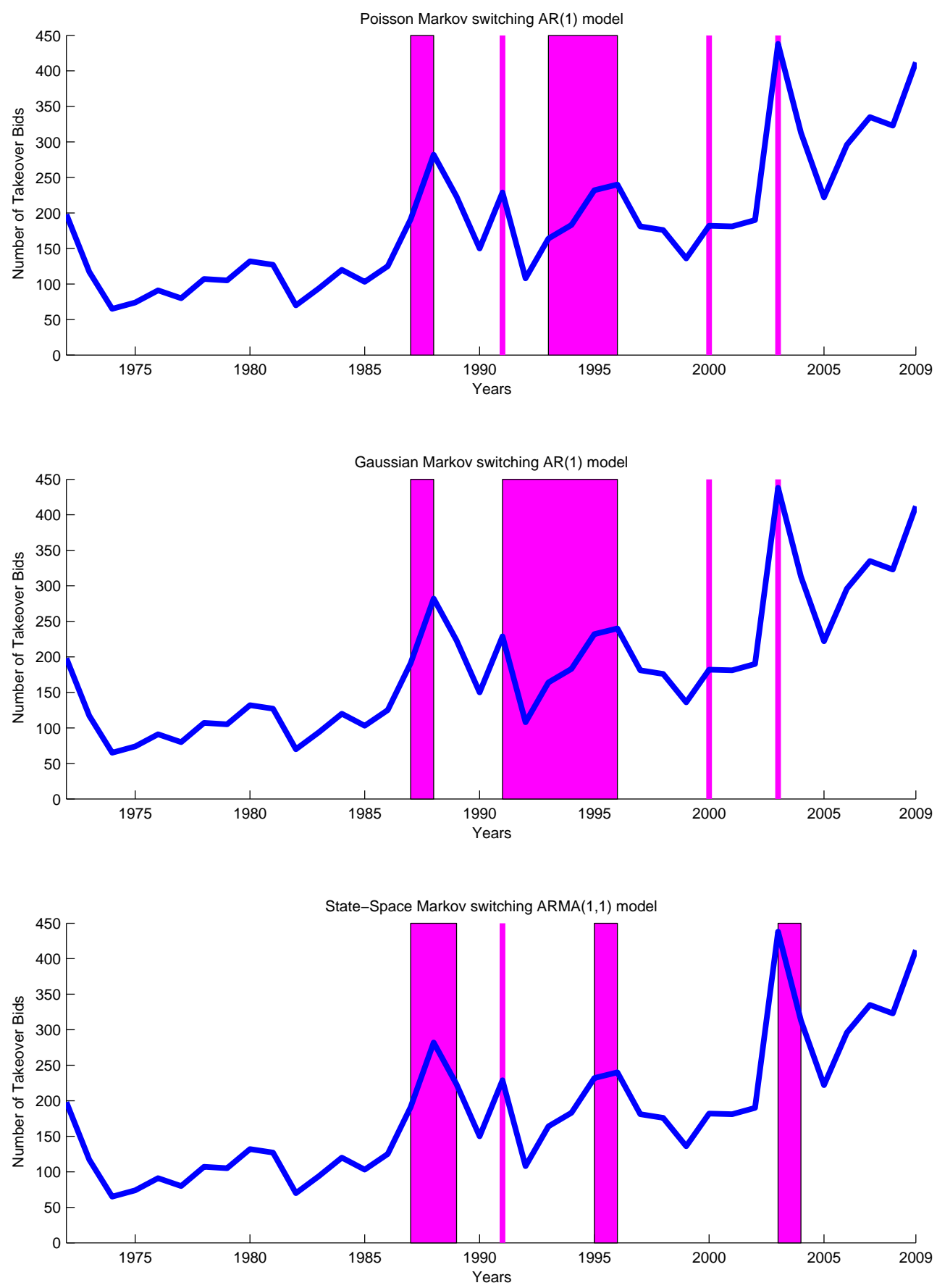

Figure 2: Time series of Australian takeover bids (1972-2009) with takeover waves identified across different Markov switching models by using data from 1972 to 2004 . 

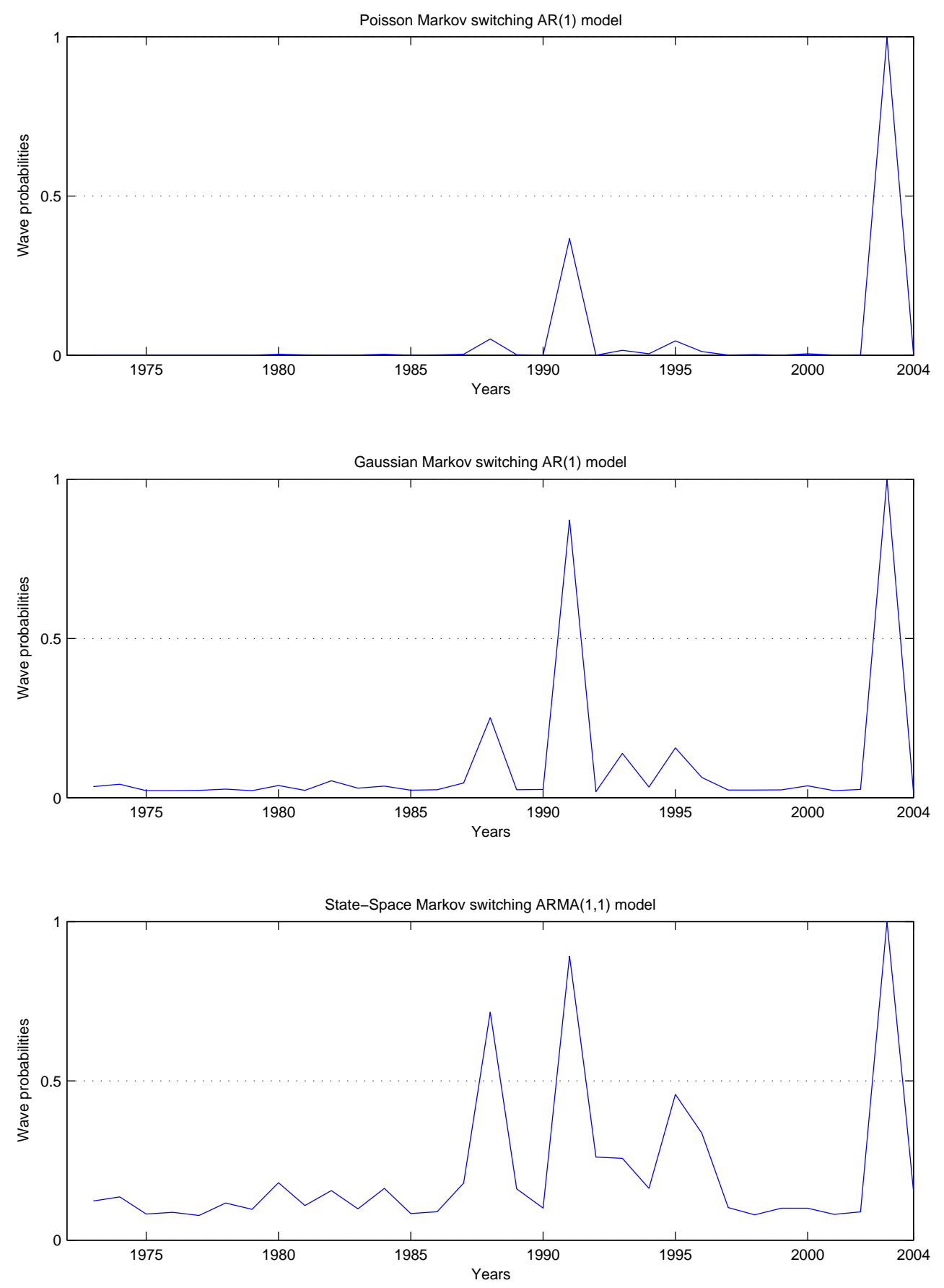

Figure 3: Proportion of takeover bids to number of listed companies 1972-2004 - the probability of the takeover process being in wave state across different Markov switching models. 

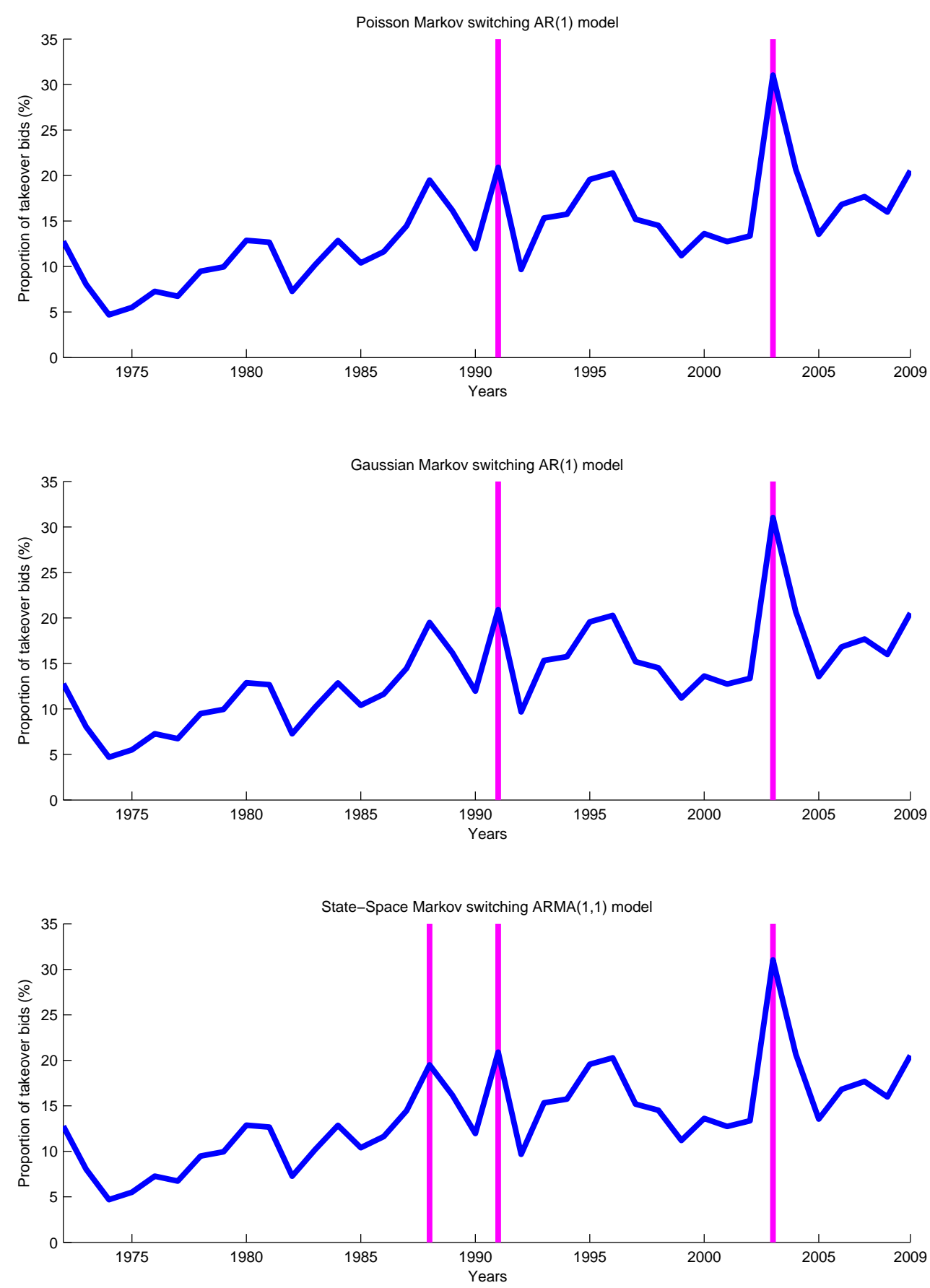

Figure 4: Time series of the proportion of takeover bids to number of ASX-listed companies (1972-2009) with takeover waves identified across different Markov switching models by using data from 1972 to 2004. 